\title{
Associated Factors for Farrowing Duration in Sows with Natural Parturition in Intensive Conditions
}

\author{
Nguyen Hoai Nam ${ }^{1 *}$ and Peerapol Sukon ${ }^{2,3}$ \\ ${ }^{I}$ Faculty of Veterinary Medicine, Vietnam National University of Agriculture, Vietnam \\ ${ }^{2}$ Faculty of Veterinary Medicine, Khon Kaen University, Thailand \\ ${ }^{3}$ Research Group for Animal Health Technology, Khon Kaen University, Thailand \\ *Corresponding author's E-mail: hoainam26061982@yahoo.com; (i) ORCiD: 0000-0002-2110-0006
}

\begin{abstract}
Modern pig farming worldwide has been facing substantial economic loss due to perinatal mortality which is mainly associated with the farrowing process. Therefore, the present study aimed to identify factors affecting the farrowing duration in natural farrowing sows in the intensive indoor conditions. In total, 210 farrowing sows in 4 commercial farms were included in the study. The association between potential risk factors and farrowing duration was analyzed by using general linear models. Two final models demonstrated that the number of total born piglets, number of stillborn and mummified piglets, litter weight, and average birth weight were significantly associated with farrowing duration. Among the four factors, average birth weight had a negative association with whereas the other three factors had positive associations with farrowing duration. Two models explained about 19.1-19.5\% variation of the farrowing duration. The results also demonstrated that the number of total born piglets, stillborn, and mummified piglets were more important than litter weight and average birth weight in explaining the variation of farrowing duration.
\end{abstract}

Keywords: Birth weight; Farrowing duration, Sow, Stillbirth, Total born

\section{INTRODUCTION}

Modern pig farming has been confronted with substantial economic loss and animal welfare problem due to perinatal mortality (van Dijk et al., 2005). A majority of stillbirth (66.8\%) occurs during expulsive stage of farrowing process, and further, about $16.4 \%$ of stillbirths occur shortly postpartum (Leenhouwers et al., 2003) with a similar disease etiology (Rangstrup-Christensen et al., 2017). Prolonged farrowing duration increases the risk of umbilical cord rupture and asphyxia (Mota-Rojas et al., 2006), which predisposes piglets to stillbirth (Borges et al., 2005; Canario et al., 2006), reduces postnatal viability by delaying first contact with udder, and lowers growth rate and survival rate over 10 days postpartum (Herpin et al., 1996) and before weaning (Rootwelt et al., 2013). Thus, farrowing duration is clearly an important indicator for survival of piglets.

Effects of various factors on farrowing duration has been investigated with controversial results (van Dijk et al., 2005; Motsi et al., 2007; Bjorkman et al., 2018). The disparity in results may be attributable to the difference in farrowing conditions (Oliviero et al., 2010), sow breeds (van Dijk et al., 2005), the increase in litter size over time (Koketsu et al., 2017), and number of factors that were investigated in different studies (van Dijk et al., 2005; Motsi et al., 2007).

The aim of this study was to evaluate effects of various factors including parity, gestation length, number of total born piglets, litter weight, average birth weight, presence or absence of stillborn and mummified piglets in a litter, and number of stillborn and mummified piglets in a litter on farrowing duration of sows raised in intensive indoor farrowing conditions.

\section{MATERIALS AND METHODS}

\section{Ethical approval}

This study was performed according to all ethics and animal rights of Vietnam National University of Agriculture, Vietnam.

\section{Animals}

Data were collected from 210 Landrace x Yorkshire crossbred sows raised in four commercial farms in three provinces (Hung Yen, Bac Giang and Thai Binh) in the North of Vietnam. All sows were artificially inseminated with semen from Duroc boars. During gestation, sows were fed 1.8-4.0 kg of commercial feed containing 13-17\% crude 
protein and metabolizable energy of 2900-3100 Kcal/kg (Hi-Gro 566, 567S, Charoen Pokphan, Vietnam). All sows were vaccinated against classical swine fever, porcine respiratory and reproductive syndrome, foot and mouth disease, porcine circovirus disease and Aujeszky's disease. Sows were kept in individual gestation crates sized about $60 \mathrm{~cm} \mathrm{x} 220 \mathrm{~cm}$. About a week before estimated farrowing date, sows were removed to farrowing crates with the size of $180 \mathrm{~cm} \times 220$ $\mathrm{cm}$. The sow area, with a slatted floor and similar size as gestation crates, was located in the middle of the farrowing crates. Water was provided ad libitum through a nipple drinking system.

\section{Data collection}

This study was conducted during June to November, 2019. In each farm, data were collected by 2 to 3 veterinarians who had been trained on data collection. Signs of milk letdown, vulva swelling, mucous secretion were monitored carefully to detect the time of parturition. Data including sows number, parity, gestation length, number of total born (NTB), number of live-born, number of stillborn, number of mummified, litter weight, average birth weight (ABW), and duration of farrowing were recorded. Gestation length was calculated as the interval from the first insemination to the date of farrowing. The NTB was calculated as sum of number of live-born, stillborn and mummified piglets. Live-born and stillborn piglets were weighted individually. Litter weight was the sum of weight of individual piglet in a given litter. Average birth weight was calculated by dividing litter weight by the number of live-born and stillborn piglets. Farrowing duration was the interval between the first and the last piglet expulsion. None of the sows were induced for parturition. Any sows that were administered oxytocin during farrowing or needed manual extraction were excluded from observation, and data of such sows were not used in any analysis.

\section{Statistical analysis}

General Linear Models (GLM) were used to determine factors that affected the farrowing duration. Farrowing duration was transformed by using natural logarithm to obtain normal distribution. Risk factors were farms, parity, gestation length, NTB, litter weight, ABW, presence or absence of stillborn and mummified piglets in a litter (PSM), and number of stillborn and mummified piglets in a litter (NSM). Initially, each factor was included in the GLM as a sole explanatory variable for farrowing duration. Only variables significant at $\mathrm{P} \leq 0.25$ (Hosmer and Lemeshow, 2000) in the univariate analysis were further analyzed in combination with others to find out suitable models. The NTB and litter weight $(\mathrm{r}=0.817, \mathrm{P}<0.01)$, PSM and NSM $(\mathrm{r}=0.651, \mathrm{P}<0.01)$ were highly correlated, thus they were analyzed in different models. Models were built up by considering the pairs of variables (NTB and NSM, NSM and litter weight, litter weight and PSM), followed by adding the third variable if the added variable conferred a significant effect signaling by a P-value $<0.05$. All statistics were carried out in Statistical Package for the Social Sciences (SPSS) version 22 (IBM SPSS Statistics for Windows, Version 22.0, Armonk, NY).

\section{RESULTS}

\section{Descriptive statistics}

In total, data from 210 litters were included in this study. The average farrowing duration was $215 \pm 122$ minutes. Of the 210 litters investigated, 64.8\% (136/210) had at least one stillborn or mummified piglet, and 61.0\% (128/210) of litters had at least one stillborn piglet. Thirty-nine out of 210 litters $(18.6 \%)$ had at least one mummified piglet. Totally, 2995 piglets were born from 210 sows, among them 2685 (89.6\%), 251 (8.4\%) and 59 (2.0\%) were live-born, stillborn and mummified piglets, respectively. Descriptive statistics of some reproductive traits of studied sows are presented in Table 1 .

Table 1. Descriptive statistics for some reproductive traits of 210 investigated sows from four farms in the North of Vietnam in 2019.

\begin{tabular}{lccc}
\hline Parameter & Mean \pm SD & Minimum & Maximum \\
\hline Parity & $4.6 \pm 2.5$ & 1 & 10 \\
Gestation length (days) & $115.3 \pm 1.8$ & 110 & 120 \\
Number of total born piglets & $14.3 \pm 3.3$ & 4 & 24 \\
Number of live-born piglets & $12.8 \pm 3.2$ & 4 & 22 \\
Number of stillborn piglets & $1.2 \pm 1.5$ & 0 & 11 \\
Number of mummified piglets & $0.3 \pm 0.6$ & 0 & 4 \\
Litter weight (kg) & $19.2 \pm 4.6$ & 4.4 & 34 \\
Average birth weight (kg) & $1.36 \pm 0.19$ & 0.84 & 1.96 \\
Farrowing duration (minutes) & $215 \pm 122$ & 22 & 1226 \\
\hline
\end{tabular}




\section{Factors influencing the farrowing duration}

At the initial stage of GLM, the log-transformed farrowing duration had no significant correlation with farms and gestation length (Table 2). In the next step, parity and PSM were rejected from final models due to their nonsignificant effect. Finally, two models were built to explain the variation of farrowing duration (Table 3). The first model contained three variables including NSM, litter weight and ABW $\left(\mathrm{R}^{2}=0.191\right)$ and the second model consisted of two variables including NTB and NSM $\left(\mathrm{R}^{2}=0.195\right)$. Univariate analysis showed that the most explanatory variables were NTB and NSM with $\mathrm{R}^{2}=0.134$ and 0.137 , respectively. The NTB, NSM, and litter weight positively correlated with farrowing duration. By contrast, ABW was negatively associated with farrowing duration.

Table 2. Univariate analysis of factors associated with log-transformed farrowing duration in 210 sows from four farms in the North of Vietnam in 2019

\begin{tabular}{lcc}
\hline Variables & Significance & Inclusion in the multivariate analysis \\
\hline Farms & 0.283 & Excluded \\
Parity & 0.202 & Included \\
Gestation length & 0.560 & Excluded \\
NTB & $<0.001$ & Included \\
Litter weight & 0.001 & Included \\
ABW & 0.005 & Included \\
PSM & 0.008 & Included \\
NSM & $<0.001$ & Included \\
\hline
\end{tabular}

NTB: number of total born piglets; ABW: average birth weight; PSM: presence or absence of stillborn and mummified piglets; NSM: number of stillborn and mummified piglets.

Table 3. Multivariate analysis of the factors associated with log-transformed farrowing duration in 210 sows from four farms in the North of Vietnam in 2019

\begin{tabular}{lcccc}
\hline Model & Parameter & Regression coefficient & 95\% CI & Significance \\
\hline \multirow{3}{*}{ Model 1 } & Intercept & 5.421 & $4.981-5.861$ & $<0.001$ \\
& NSM & 0.075 & $0.039-0.110$ & $<0.001$ \\
& Litter weight & 0.022 & $0.008-0.036$ & 0.002 \\
Model 2 & ABW & -0.504 & $-0.831-(-0.176)$ & 0.003 \\
& Intercept & 4.638 & $4.381-4.895$ & $<0.001$ \\
\hline
\end{tabular}

NSM: number of stillborn and mummified piglets; ABW: average birth weight; NTB: number of total born piglets; CI; confidence interval; Model 1 conferred a $\mathrm{R}^{2}=0.191$; Model 2 conferred a $\mathrm{R}^{2}=0.195$.

\section{DISCUSSION}

The farrowing duration has been reported to range between 130 and 396 minutes (van Rens and van der Lende, 2004; van Dijk et al., 2005; Oliviero et al., 2010; Bjorkman et al., 2017). The result of present study was very close to the findings obtained by Motsi et al. (2007) who demonstrated that average farrowing duration of 136 sows was $217 \pm 160$ minutes. The incidence of stillbirth at litter level in the present study $(61.0 \%)$ was higher than the results reported by Cozler et al. (2002) and Borges et al. (2005). However, the stillbirth rate (8.4\%) was still in the range of previous reported results (Lucia et al., 2002; Borges et al., 2005; Vanderhaeghe et al., 2010; Nam and Sukon, 2020).

The nonsignificant effect of parity on farrowing duration in this study confirmed the findings by several other works (Fahmy and Friend, 1981; van Dijk et al., 2005; Motsi et al., 2007; Oliviero et al., 2010). However, it did not agree with results found by Bjorkman et al. (2017) who reported that parity was positively correlated with farrowing duration. The disparity in results among studies may be due to the difference in methods of analysis. Whereas Bjorkman et al. (2017) evaluated effects of parity on farrowing duration without adjustment for other factors, the present study and others (van Dijk et al., 2005; Oliviero et al., 2010) did that in combination with other variables. The nonsignificant effect of parity on farrowing duration in the present study may be attributable to relatively high proportion of high parity sows. Sows at higher parity might have been more strictly selected based on their reproductive criteria including the farrowing duration. Thus, the selection may exert their effect on the heterogeneity of farrowing duration among different parities, and may thereby alleviate the effect of parity on farrowing duration. 
This study failed to detect any significant effect of gestation length on farrowing duration. This finding confirmed the results of Oliviero et al. (2010). Some authors found a positive correlation between these two criteria (Fahmy and Friend, 1981), by contrast, others found a negative association (van Dijk et al., 2005). Gestation length had a negative correlation with litter size (Sasaki and Koketsu, 2007; Rydhmer et al., 2008), thus it was expected to have a negative association with farrowing duration. However, in the current study, such association between gestation length and litter size did not exist, giving a possible explanation for the nonsignificant association between gestation length and farrowing duration.

It is not clear whether long farrowing duration induces stillbirth or stillbirth increases farrowing duration (van Dijk et al., 2005). Many studies found a positive association between these two factors (Borges et al., 2005; van Dijk et al., 2005; Canario et al., 2006). Also, Motsi et al. (2007) substantiated that PSM was positively correlated with farrowing duration. By contrast, current study failed to detect any significant effect of PSM on farrowing duration. Firstly, it was possible that the association between PSM and other factors such as litter weight $(\mathrm{r}=0.269, P<0.01)$ and ABW $(\mathrm{r}=-$ $0.168, P<0.05)$ alleviated the effect of PSM on farrowing duration when they were put in the same models. Secondly, using PSM as an explanatory variable for farrowing duration erroneously implies that all litters with stillborn and/or mummified have equal number of these piglet types. Thus, NSM may be a better factor than PSM for explaining variation of farrowing duration because it represents the quantity of stillborn and/or mummified piglets. Indeed, this study found that increased NSM elevated farrowing duration. This result confirmed many previous findings by several authors (van Dijk et al., 2005; Oliviero et al., 2010; Bjorkman et al., 2017). A possible reason for the finding was that only live piglets could actively move through the pelvic canal (Taverne and van der Weijden, 2008), therefore, dead piglets could not participate into the farrowing process to obtain a right position, resulting in increased farrowing duration (van Dijk et al., 2005).

Positive association between farrowing duration and NTB in this study corroborated previous findings (Fahmy and Friend, 1981; van Dijk et al., 2005). Another study found the association between number of live-born, instead of NTB, and farrowing duration (Motsi et al., 2007). In the current study, the number of live-born was not included in the analysis because this factor did not confer practical significance for plans to reduce farrowing duration and stillbirth. On one hand, increased NTB increased litter weight $(\mathrm{r}=0.817, \mathrm{P}<0.01)$, and as the consequence, the litter weight also positively correlated with the farrowing duration. However, this result was not in the agreement with previous study that detected no association between litter weight and farrowing duration (Motsi et al., 2007). It was not a surprise because that study did not find any correlation between NTB and farrowing duration. On the other hand, increased NTB resulted in decreased ABW ( $\mathrm{r}=-0.267, P<0.01)$, therefore, this study found a negative association between ABW and farrowing duration. This finding was in contrast to the previously published results that demonstrated a positive association between ABW and farrowing duration (Motsi et al., 2007). Bigger piglets, in comparison with their small littermates, may have thicker placenta, and they need more time to break the placenta to start their journey through uterus towards the birth canal (van Rens and van der Lende, 2004). They are also subjected to higher friction on the walls of the birth canal (Motsi et al., 2007). Collectively, it takes longer time for heavier piglets to be delivered. However, as mentioned above, ABW was negatively associated with NTB, and it seemed that, in comparison with ABW, NTB had a stronger effect on farrowing duration. Indeed, in this study the NTB explained 13.4\% variation of farrowing duration compared with $3.7 \%$ by $\mathrm{ABW}$. Therefore, increased $\mathrm{ABW}$ reduced farrowing duration.

\section{CONCLUSIONS}

This study demonstrated that the number of total born piglets and the number of stillborn and mummified piglets in a litter were the most important factors affecting duration of farrowing of sows in an intensive system. Litter weight and average birth weight also affected farrowing duration but to a lesser extent.

\section{DECLARATIONS}

\section{Acknowledgements}

The authors are grateful to Luong Van Dung, Nguyen Thi Thu, Nguyen Thi Ngan, Nguyen Thi Hong Nhung, Tran Van Hoa, Nguyen The Nam, Hoang Thi Quynh, Nguyen Thi Sinh, Dang Van An for their assistance in data collection.

\section{Competing interests}

The authors declare that there is no conflict of interests.

\section{Authors' contribution}

NHN collected data. NHN and PS conceived and designed the study, analyzed data and wrote the manuscript. Both authors approved the final manuscript. 


\section{REFERENCES}

Bjorkman S, Oliviero C, Kauffold J, Soede NM and Peltoniemi OAT (2018). Prolonged parturition and impaired placenta expulsion increase the risk of postpartum metritis and delay uterine involution in sows. Theriogenology, 106: 87-92. DOI: https://doi.org/10.1016/j.theriogenology.2017.10.003

Bjorkman S, Oliviero C, Rajala-Schultz PJ, Soede NM and Peltoniemi OAT (2017). The effect of litter size. parity and farrowing duration on placenta expulsion and retention in sows. Theriogenology, 92: 36-44. DOI: https://doi.org/10.1016/j.theriogenology.2017.01.003.

Borges VF, Bernardi ML, Bortolozzo FP and Wentz I (2005). Risk factors for stillbirth and foetal mummification in four Brazilian swine herds. Preventative Veterinary Medicine, 70: 165-76. DOI: https://doi.org/10.1016/j.prevetmed.2005.03.003.

Canario L, Cantoni E, Le Bihan E, Caritez JC, Billon Y, Bidanel JP and Foulley JL (2006). Between-breed variability of stillbirth and its relationship with sow and piglet characteristics. Journal of Animal Science, 84: 3185-3196. DOI: https://doi.org/10.2527/jas.2005-775.

Cozler YL, Guyomarc'h C, Pichodo X, Quinio PY and Pellois H (2002). Factors associated with stillborn and mummified piglets in high-prolific sows. Animal Research, 51: 261-268. DOI: https://doi.org/10.1051/animres:2002017.

Fahmy MH and Friend DW (1981). Factors influencing, and repeatability of the duration of farrowing in Yorkshire sows. Canadian Journal of Animal Science, 61: 17-22. Available at: https://www.nrcresearchpress.com/doi/abs/10.4141/cjas81-003\#.X1NBdzIzbIX

Herpin P, Le Dividich J, Hulin JC, Fillaut M, De Marco F and Bertin R (1996). Effects of the level of asphyxia during delivery on viability at birth and early postnatal vitality of newborn pigs. Journal of Animal Science, 74: 2067-2075. DOI: https://doi.org/10.2527/1996.7492067x.

Hosmer WD and Lemeshow S (2000). Applied logistic regression. 2nd Edition. John Wiley \& Sons, Inc. USA, p. 95

Koketsu Y, Tani S and Iida R (2017) Factors for improving reproductive performance of sows and herd productivity in commercial breeding herds. Porcine Health Management, 3:1. Available at: https://www.ncbi.nlm.nih.gov/pmc/articles/PMC5382409/.

Leenhouwers JI, Wissink P, Van der Lende T, Paridaans H and Knol EF (2003) Stillbirth in the pig in relation to genetic merit for farrowing survival. Journal of Animal Science, 81: 2419-2424. DOI: https://doi.org/10.2527/2003.81102419x.

Lucia Tjr, Correa MN, Deschamps JC, Bianchi I, Donin MA, Machado AC, Meincke W and Matheus JE (2002). Risk factors for stillbirths in two swine farms in the south of Brazil. Preventative Veterinary Medicine, 53: 285-292. DOI: https://doi.org/10.1016/S0167-5877(01)00288-4.

Mota-Rojas D, Trujillo ME, Martinez J, Rosales AM, Orozco H, Ramirez R, Sumano H and Alonso-Spilsbury M (2006). Comparative routes of oxytocin administration in crated farrowing sows and its effects on fetal and postnatal asphyxia. Animal Reproduction Science, 92: 123-143. DOI: https://doi.org/10.1016/j.anireprosci.2005.04.012.

Motsi P, Sakuhuni C, Halimani TE, Bhebhe E, Ndiweni PNB and Chimonyo M (2007). Influence of parity, birth order, litter size and birth weight on duration of farrowing and birth intervals in commercial exotic sows in Zimbabwe. Animal Science, 82: 569-574. DOI: https://doi.org/10.1079/ASC200664.

Nam NH. Sukon P (2020). Risk factors associated with stillbirth in swine farms in Vietnam. World's Veterinary Journal, 10 (1): 74-79. DOI: https://dx.doi.org/10.36380/scil.2020.wvj10

Oliviero C, Heinonen M, Valros A and Peltoniemi O (2010). Environmental and sow-related factors affecting the duration of farrowing. Animal Reproduction Science, 119: 85-91. DOI: https://doi.org/10.1016/j.anireprosci.2009.12.009.

Rangstrup-Christensen L, Krogh MA Pedersen LJ and Sorensen JT (2017). Sow-level risk factors for stillbirth of piglets in organic sow herds. Animal, 11: 1078-1083. DOI: https://doi.org/10.1017/S1751731116002408.

Rootwelt V, Reksen O, Farstad W and Framstad T (2013). Postpartum deaths: piglet, placental, and umbilical characteristics. Journal of Animal Science, 91: 2647-2656. DOI: https://doi.org/10.2527/jas.2012-5531.

Rydhmer L, Lundeheim N and Canario L (2008). Genetic correlations between gestation length, piglet survival and early growth. Livestock Science, 115: 287-293. DOI: https://doi.org/10.1016/j.livsci.2007.08.014.

Sasaki Y and Koketsu Y (2007). Variability and repeatability in gestation length related to litter performance in female pigs on commercial farms. Theriogenology, 68: 123-127. DOI: https://doi.org/10.1016/j.theriogenology.2007.04.021.

Taverne MA and Van der Weijden GC (2008). Parturition in domestic animals: targets for future research. Reproduction in Domestic Animals, 43 (Suppl 5): 36-42. DOI: https://doi.org/10.1111/j.1439-0531.2008.01219.x.

Van Dijk AJ, Van Rens B, Van der Lende T and Taverne M (2005). Factors affecting duration of the expulsive stage of parturition and piglet birth intervals in sows with uncomplicated, spontaneous farrowings. Theriogenology, 64: 1573-1590. DOI: https://doi.org/10.1016/j.theriogenology.2005.03.017.

Van Rens BT and Van der Lende T (2004). Parturition in gilts: duration of farrowing, birth intervals and placenta expulsion in relation to maternal, piglet and placental traits. Theriogenology, 62: 331-352. DOI: https://doi.org/10.1016/j.theriogenology.2003.10.008.

Vanderhaeghe C, Dewulf J, De Vliegher S, Papadopoulos GA, de Kruif A and Maes D (2010). Longitudinal field study to assess sow level risk factors associated with stillborn piglets. Animal Reproduction Science, 120: 78-83. DOI: https://doi.org/10.1016/j.anireprosci.2010.02.010. 